\title{
Allgemeine Kennzeichnung „Factoring“
}

Factoring etabliert sich immer stärker im Mittelstand. Viele Unternehmen nutzen die Chance, Rechnungen an ein Factoring-Unternehmen zu verkaufen und schneller an liquide Mittel zu kommen. Damit verbessern sie die Bedingungen für ihre Finanzierung: Das Volumen der Forderungen nimmt ab, die Bonität dagegen zu. Das wirkt sich positiv auf das Rating bei Banken aus. Im ersten Halbjahr 2018 stieg der Umsatz der Mitgliedsunternehmen im Deutschen Factoring-Verband im Vergleich zum Vorjahreszeitraum um fünf Prozent auf knapp 119 Milliarden Euro. Die Zahl der Unternehmen, die Factoring-Dienstleistungen in Anspruch nehmen, stieg um mehr als 25 Prozent auf 44300.

Weiter stark auf Wachstumskurs ist das sogenannte B2C-Factoring: Der Umsatz stieg um 14 Prozent auf 2,3 Milliarden Euro. Dabei finanzieren Factoring-Unternehmen Forderungen gegen Konsumenten. Das Angebot wächst besonders im Onlinehandel und im medizinischen Sektor.

Beim Factoring verkauft ein Unternehmen seine Forderungen aus Warenlieferungen und Dienstleistungen gegen seine Kunden fortlaufend an ein Factoringinstitut. Auf diese Weise erhält das Unternehmen sofortige Liquidität unmittelbar aus seinen Außenständen und steht quasi so, als wenn alle seine Kunden sofort bezahlen würden. Der von Factoringinstituten zudem regelmäßig gebotene Ausfallschutz, die sog. Delkredereabsicherung, und laufend aktuelle Informationen über die Bonität der jeweiligen Abnehmer (die Debitoren) garantieren sichere Vertriebswege für Factoring nutzende Unternehmen.

Grundlage der Geschäftsbeziehung zwischen Factor und Factoringkunde ist ein gesetzlich nicht geregelter Factoringvertrag, der rechtlich gesehen nach $\S 305$ BGB ein Kaufvertrag ist. Der Kauf wird durch Abtretung der Debitorenforderungen erfüllt.

Factoring ist keine Finanzierungsform, die Unternehmen wählen, wenn sie in Finanznot sind. Factoring ist eine Finanzierungsform, die insbesondere bonitätsmäßig einwandfreien Factoringkunden angeboten wird. Schon aus Gründen finanziellen Eigeninteresses achten Factoringinstitute ähnlich wie Banken auf eine gesunde Kunden- und Abnehmerstruktur ihrer Factoringpartner: Nur gesunde Unternehmen mit werthaltigen Forderungen, guter Bonität und sicherer Ertragskraft eignen sich für eine regelmäßig langfristig ausgerichtete Factoringbeziehung. Factoring kommt dabei für sehr viele Branchen in Betracht. Schwerpunktkundenbranchen sind z. B. Metallerzeugung und Metallverarbeitung, Verarbeitendes Gewerbe, Ernährungsgewerbe, Handelsvermittlung und Großhandel. 